\title{
Macroglossia following intracranial injury
}

\author{
Ilona Juan, MD · Alan Nova, DO • Brian Lemkuil, MD · Arthur Lam, MD · \\ Jamie Nicole LaBuzetta, MD
}

Received: 9 March 2020/Revised: 4 April 2020/Accepted: 4 April 2020/Published online: 21 April 2020

(c) Canadian Anesthesiologists' Society 2020

\section{To the Editor,}

Macroglossia is a rare yet potentially fatal complication of neurosurgical procedures involving the posterior fossa and lasting longer than six hours. Three pathophysiologic mechanisms are proposed: (1) impaired venous drainage due to dependent tongue positioning; (2) venous drainage obstruction with neck flexion/rotation; and (3) reperfusion injury following arterial hypoperfusion resulting in oropharyngeal swelling and airway obstruction. ${ }^{1-3} \mathrm{We}$ describe two neurosurgical patients who developed macroglossia because of prolonged intubation after brief posterior fossa craniotomies, which is a previously undescribed clinical context for this complication.

A 40-yr-old woman with cerebellar hemorrhage underwent a four-hour craniotomy in the prone position. She remained intubated postoperatively and macroglossia was noted on the first postoperative day (POD) (Figure a). Tracheostomy was performed on POD 6 and bilateral masseter Botox ${ }^{\circledR} \quad$ (OnabotulinumtoxinA, Allergan Pharmaceuticals, Madison, NJ, USA) injections (40 units total) were administered on POD 8 without improvement in

I. Juan, MD ( $ه)$

Department of Anaesthesiology, University of California San

Diego, San Diego, CA, USA

e-mail: ijuan@health.ucsd.edu

A. Nova, DO - J. N. LaBuzetta, MD

Division of Neurocritical Care, Department of Neurosciences, University of California San Diego, San Diego, CA, USA

B. Lemkuil, MD · A. Lam, MD

Department of Anaesthesiology, University of California San

Diego, San Diego, CA, USA

Division of Neurocritical Care, Department of Neurosciences, University of California San Diego, San Diego, CA, USA lingual swelling. Intravenous dexamethasone $(10 \mathrm{mg})$ was given on PODs 15, 19, and 23 with modest improvement. Dental bite blocks were inserted on POD 19, and her macroglossia ultimately resolved on POD 28.

A 70-yr-old woman with previously coiled right internal carotid artery aneurysm experienced a subarachnoid hemorrhage due to aneurysm rupture. She underwent aneurysm clipping in the supine position lasting less than six hours. On POD 11 she developed refractory status epilepticus requiring re-intubation, after which she developed progressive macroglossia (Figure b). Tracheostomy was performed and dental bite blocks inserted on POD 19. Macroglossia regressed by POD 24.

Updated practice guidelines on clinical management of macroglossia are lacking. Acute airway management is a critical first step, and re-intubation/tracheostomy may be necessary to maintain ventilation. Of reported macroglossia cases requiring re-intubation, 55\% were described as difficult. $^{4}$ We do not recommended placement of an oropharyngeal airway in these circumstances because there is a risk of stress on already compromised vasculature.

Complications related to ongoing tongue protrusion must also be addressed. We hypothesize that pressure exerted by teeth leads to venous compression and ischemic pressure-related myonecrosis. Drying of the tongue can result in fissuring and superficial infection leading to further tissue injury. Our experience suggests silicone dental bite blocks (Angzhili, PlastCare USA, Los Angeles, CA, USA) best resist dislodgement by the patient and are most effective in resolving macroglossia compared with conventional soft bite blocks.

The objective of Botox ${ }^{\circledR}$ injection was to relax the oropharyngeal structures and minimize repetitive trauma on the tongue. There are no studies to date evaluating the 
Figure (a) Patient 1: macroglossia and tissue breakdown on postoperative day 12. (b) Patient 2: macroglossia with lingual ulceration on postoperative day 22

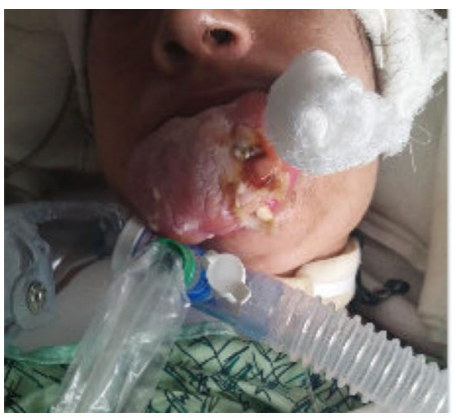

(a)

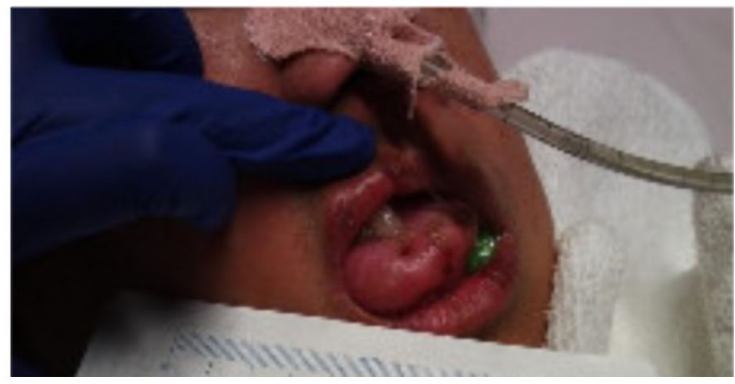

(b) efficacy and dosage of Botox ${ }^{\circledR}$ injections for macroglossia treatment; the suggested dose for sialorrhea management is 75 units per submandibular gland. ${ }^{5}$ It is possible the dose administered to our patient was inadequate. The peak effect of Botox ${ }^{\circledR}$ may take up to 1 week to develop suggesting an interim strategy is required. Increasing dose or frequency of corticosteroids may be considered but must be balanced by impaired wound healing and hyperglycemia in the critically ill patient.

It is the shared responsibility of the surgeon and anesthesiologist to maximize strategies to prevent macroglossia. Excessive neck flexion/rotation in high-risk patients should be avoided. We promote venous drainage by maintaining a minimum of two fingerbreadths between mandible and clavicle and reverse Trendelenburg positioning of the patient. Intermittent oropharyngeal checks should be performed and the tracheal tube retained and/or repositioned if supraglottic edema is present.

In conclusion, patients undergoing brief intracranial procedures and those requiring prolonged tracheal intubation are at risk for developing macroglossia. Macrosglossia can be associated with significant morbidity in our neurosurgically and neurocritically ill patients. We highlight the need for increased awareness and prevention of this complication among anesthesiologists, neurosurgeons, and critical-care physicians.
Conflicts of interest None.

Funding statement None.

Consent for publication Patient consent was obtained from each patient or his/her family member.

Editorial responsibility This submission was handled by Dr. Gregory L. Bryson, Deputy Editor-in-Chief, Canadian Journal of Anesthesia.

\section{References}

1. Lam AM, Vavilala MS. Macroglossia: compartment syndrome of the tongue? Anesthesiology 2000; 92: 1832-5.

2. Moore JK, Chaudhri S, Moore AP, Easton J. Macroglossia and posterior fossa disease. Anaesthesia 1988; 43: 382-5.

3. McAllister RG. Macroglossia: a positional complication. Anesthesiology 1974; 40: 199-200.

4. Tattersall MP. Massive swelling of the face and tongue: a complication of posterior cranial fossa surgery in the sitting position. Anaesthesia 1984; 39: 1015-7.

5. Lipp A, Trottenberg T, Schink T, Kupsch A, Arnold G. A randomized trial of botulinum toxin A for treatment of drooling. Neurology 2003; 61: 1279-81.

Publisher's Note Springer Nature remains neutral with regard to jurisdictional claims in published maps and institutional affiliations. 